\title{
Stumped; the Achilles of Laparoscopic Appendectomy
}

\author{
Michael E. Kelly • Des C. Winter
}

Received: 16 April 2014 / Accepted: 22 April 2014 / Published online: 6 May 2014

(C) 2014 The Society for Surgery of the Alimentary Tract

Mc Burney described a surgical technique that was quick, easy and inexpensive with low rates of morbidity and mortality. ${ }^{1,2}$ It remained the gold standard for the next century. However, the introduction of laparoscopic appendectomy in the 1980s advanced the tide of change toward minimally invasive surgery. ${ }^{3}$ Its popularity evolved at a time when there was an emphasis on "new" techniques coupled with reduced length of stay in hospital. The advantages of the approach included better visualization of the abdomen, less postoperative pain, faster recovery, reduced hospital stay, better cosmesis, and reduced wound infections. ${ }^{4,5}$ The role of diagnostic laparoscopy became favoured by many surgeons as they were able to inspect the abdominal cavity initially and avoid appendectomy if appendicitis was not found.

Despite the aforementioned benefits, laparoscopic appendectomy is plagued with more than double the number of intra-abdominal abscess post-operatively. ${ }^{6,7}$ The conscious drive for minimally invasive surgery has obscured the fundamental differences between open and laparoscopic appendectomy. In the majority of open appendectomies, the appendiceal stump is invaginated or buried. Speculation suggests that this technique significantly reduces the chance of spillage of pathogens and hence peritonitis. ${ }^{8}$ Furthermore, there is improved healing of the gut via the formation of collagen and granulation tissue from the serosal layer of the caecum. In contrast, ligation of the appendix with preformed Roeder knots are most commonly used in laparoscopic appendectomy. It has been hypothesized that loosening of such ligatures can occur due to mucosal necrosis, resulting in leakage. ${ }^{9}$

M. E. Kelly $(\bowtie) \cdot$ D. C. Winter

Department of Surgery, St Vincent's University Hospital, Dublin, Ireland

e-mail: kellym11@tcd.ie
Intra-abdominal abscess is a potentially lethal complication resulting in prolonged hospital stay with many patients requiring intervention, radiological or even surgical drainage of the abscess. This has considerable resource implications, which negate the benefit of a laparoscopic approach. Observational studies show abscess formation in $0.5-1 \%$ and $2-5 \%$ of patients following open and laparoscopic appendectomy, respectively. In addition, these rates dramatically increase when treating a perforated appendix ( $4 \%$ in open vs. $24 \%$ in laparoscopic appendectomy). ${ }^{8}$ As a result, many surgeons have reverted to an open approach in the setting of a perforated appendix.

Some surgeons speculate that a pneumoperitoneum causes diffusion and dissemination of infection throughout the abdominal cavity. ${ }^{8}$ However, if this was the case, one would expect multiple abscesses throughout the abdominal cavity. The majority of post appendectomy abscesses tend to be localized to the right lower quadrant. Though many publications have compared the complication rates after laparoscopic and open appendectomy, none specify clearly whether the appendiceal stump was invaginated in the open or laparoscopic approach. A study comparing abscess formation rates after both laparoscopic and open appendectomy with or without stump invagination would be beneficial.

In recent years, there is a growing volume of surgeons who propose the use of laparoscopic stapler devices as a better means of stump closure. The application of a stapler (especially in complicated appendicitis) reduces faecal spillage and provides a reproducibly secure stump closure without the heterogeneity of ligation of the protruding mucosa. ${ }^{9}$ However, this has generated heated debates around the expense of such practice. ${ }^{9,10}$ Alternatively, a laparoscopic purse-string device that facilitates closure and invagination would be a useful development. Perhaps the surgical community should rekindle old principles that stood the test of time; open 
appendectomy had little wrong with it, and not burying the stump could turn out to be a costly omission.

Acknowledgments The corresponding author has the right to grant on behalf of all authors and does grant on behalf of all authors, a worldwide licence

Conflict of Interest All authors declare no conflict of interests.

\section{References}

1. Mc Burney C. The incision made in the abdominal wall in cases of appendicitis, with description of a new method of operating. Ann Surg 1894;20:38

2. Eriksson S, Granstrom L. Randomized controlled trial of appendicectomy versus antibiotic therapy for acute appendicitis. Br J Surg 1995;82:166-169

3. Semm K. Endoscopic appendectomy. Endoscopy 1983;15:59-64
4. Guller U, Hervey S, Purves H et al. Laparoscopic versus open appendectomy: outcomes comparison based on a large administrative database. An Surg 2004;239:43-52

5. Chung RS, Rowland DY, Li P, Diaz J. A meta-analysis of randomized controlled trials of laparoscopic versus conventional appendectomy. J Am Coll Surg 1998; 186:545-553

6. Sauerland S, Lefering R, Neugebauer EAM. Laparoscopic versus open appendectomy for suspected appendicitis. Cochrane database of systematic reviews. 2004 Issue 3. CD001546 doi: $10.1002 / 14651858$

7. Pedersen AG, Petersen OB, Wara P, Renning H, Qvist N, Laurberg S. Randomized control trial of laparoscopic versus open appendectomy. Br J Surg 2001;88:200-2005

8. Krisher SL, Browne A, Dibbins A, Tkacz N, Curci M. Intraabdominal abscess after laparoscopic appendectomy for perforated appendicitis. Arch Surg 2001;136:438-441

9. Beldi G, Vorburger SA, Bruegger LE, Kocher T et al. Analysis of stapling versus endoloops in appendiceal stump closure. Br J Surg 2006;93:139-1393

10. Kazemier G, in't Hof KH, Bonjer HJ, Sauerland S. Securing the appendiceal stump in laparoscopic appendectomy: evidence for routine stapling? Surg Endosc 2006;20:1473-1476 